\title{
Sistema Estadual de Cultura do RJ: desafios da institucionalização de políticas públicas participativas no campo cultural fluminense (2009-2019)1
}

\author{
Sistema Estatal de Cultura de Río de Janeiro: \\ desafíos de la institucionalización de políticas públicas participativas \\ en el ámbito cultural (2009-2019)
}

State System of Culture of Rio de Janeiro: challenges of the institutionalization of participatory public policies in the cultural field (2009-2019)

\author{
Simone Amorim 2 \\ Juliano Borges ${ }^{3}$
}

\author{
Palavras-chave: \\ Política cultural \\ Instituições públicas \\ Rio de Janeiro \\ Plano Estadual \\ de Cultura
}

\section{Resumo:}

O trabalho analisa o processo de criação do Sistema Estadual de Cultura do Rio de Janeiro (2009-2019), destacando as contradições na implantação de políticas públicas participativas, diante dos limites de compromisso entre o poder público e a sociedade civil. Com o intuito de entender e dimensionar as dificuldades e os avanços obtidos, o artigo propõe uma análise empírica do caso fluminense fundamentado sobre o aporte teórico neoinstitucionalista. $\mathrm{O}$ artigo pretende contribuir para que administradores públicos possam observar erros e acertos dessa experiência em processos de gestão que envolvam a participação social e apresenta uma atualização do quadro geral das políticas de cultura no Rio de Janeiro, profundamente deterioradas pela crise institucional que afeta o estado desde 2016 .

\footnotetext{
1 Texto recebido em 02/10/2019 e aceito para publicação em 23/10/2019

Z S Simodrigues Amorim. Doutora em Políticas Púbicas e Formação Humana pela Universidade do Estado do Rio de Janeiro. Pesquisadora pós-doc junto ao ISEG/Universidade de Lisboa, Portugal. Contato: xsimoneamorimx@gmail.com - https://orcid.org/0000-0002-0015-3774

3 Juliano Borges. Doutor em Ciência Política (IUPERJ) e professor titular do curso de Comunicação Social do IBMEC-RJ, Brasil. E-mail: julianoborges@gmail.com
} 


\section{Resumen:}

El trabajo analiza el proceso de creación del Sistema Estatal de Cultura de Río de Janeiro (2009-2019), destacando las contradicciones en la implantación de políticas públicas participativas, frente a los límites del compromiso entre el poder público y la sociedad civil. Con el fin de entender y dimensionar las dificultades y los avances obtenidos, el artículo propone un análisis empírico del caso Fluminense, fundamentado en el aporte teórico neoinstitucionalista. El artículo contribuye a que administradores públicos puedan observar errores y éxitos de esta experiencia en procesos de gestión que involucran la participación social y también se presenta una actualización del cuadro general de las políticas culturales en Río de Janeiro, profundamente deterioradas por la crisis institucional que afecta al estado desde 2016.

\section{Palabras clave:}

Política cultural

Instituiciones públicas

Rio de Janeiro Plano

Estadual

de Cultura

\section{Keywords:}

Cultural Policy

Public Institutions

Rio de Janeiro

State Culture Plan

\section{Abstract:}

The paper analyzes the process of creating the Rio de Janeiro's State System of Culture (2009-2019), highlighting the contradictions in the implementation of participatory public policies, facing the limits of commitment between public power and civil society. In order to understand and measure the difficulties and advances obtained, the article proposes an empirical analysis of the Fluminense case based on the neo-institutionalist theoretical contribution. The article intends to contribute so that public administrators can observe errors and successes of this experience in management processes that involve social participation and presents an update of the general framework of cultural policies in the state of Rio de Janeiro, deeply deteriorated by the institutional crisis that affects the state since 2016 . 


\section{Sistema Estadual de Cultura do RJ: desafios da institucionalização de políticas públicas participativas no campo cultural fluminense (2009-2019)}

\section{Apresentação}

A realização da I Conferência Nacional de Cultura, em 2005, inaugu-ra um diálogo inédito entre os governos federal, estaduais e municipais; e entre produtores, gestores, artistas e pesquisadores do campo cultural, por meio de novas formas institucionais estimuladas pelo Ministério da Cultura. Tendo como pano de fundo a proposta ambiciosa de construção participativa de um Siste-ma Nacional de Cultura, à semelhança do modelo do Sistema Único de Saúde (SUS), novas políticas de financiamen-to, de gestão de equipamentos e de ampliação da participação popular na definição da agenda do setor possibilitaram a criação e o fortalecimento de espaços deliberativos mais plurais no campo da cultura brasileira.

Essa conjuntura favoreceu, por exemplo, a realização (inédita até 2005) de conferências de cultura e que fossem criados conselhos paritários entre o poder público e a sociedade, além de suscitar um debate sobre fundos de cultura e a criação de planos decenais. Essas ações, entre outras, permitiriam a negociação das prioridades no investimen-to dos recursos públicos, de modo que políticas de gabinete, pensadas 'para' e não 'com' a sociedade pudessem gradualmente deixar de ser a característica da pasta. Visões críticas analisam essa mudança (BOTELHO, 2001; RUBIM, 2008; CALABRE, 2009), protagonizada pelos órgãos da gestão pública, como a possibilidade de ruptura do histórico de descontinuidades e autoritarismos que desde o período inaugural, na década de 1930, caracterizam as políticas culturais brasileiras.

Implementadas em quase todas as unidades federativas, no estado do Rio essas transformações começaram no final de 2009, quando pela primeira vez a Secretaria de Estado de Cultura do Rio de Janeiro (SEC-RJ) propôs a construção de políticas participativas de longo prazo, por meio de um plano decenal sujeito a revisões periódicas, não restritas à classe artística e construídas em conjunto com todos os municípios do estado.

Esse processo, depois de uma ampla consulta pública (online e presencial), que envolveu a visita da SEC-RJ a todos os 92 municípios fluminenses, oito conferências regionais pelo estado e o envolvimento de mais de cinco mil participantes, acabou por consolidar a articulação que culminou com a criação do Sistema Estadual de Cultura, sancionado pelo governador após votação favorável da Assembleia Legislativa do Estado do Rio de Janeiro (ALERJ), por meio da Lei 7.035, em 7 de julho de 2015.

Contudo, a despeito de um iné-dito empenho de mobilização para a participação social e da qualidade dos documentos aprovados, o processo é marcado também por desencontros e paralisações preocupantes, sobretudo após 2016, quando a implantação do Sistema foi estagnada. Diante disso, a questão que se coloca é em que medida a derrocada dos pressupostos participativos tem a capacidade de fazer ruir todo o edifício erigido no campo cultural, no estado fluminense, onde institucionalmente foi implementado um conjunto de ações de qualificação geral das condições organizacionais da cultura.

Apenas um ano depois de sua aprovação, o Sistema Estadual de Cul- 
tura se viu ameaçado por retrocessos quando uma proposta de extinção da SEC-RJ foi encaminhada pelo Poder Executivo (sendo posteriormente revertida em favor da ampla mobilização da sociedade civil) e o compromisso com

o fortalecimento de políticas democráticas, transparentes e plurais perdeu-se diante dos sucessivos desmontes institucionais sofridos pela pasta.

Em 2019, passados quatro anos desde a formalização dos mecanismos participativos estabelecidos pela Lei do Sistema Estadual de Cultura, propomos analisar as condições em que eles foram gestados para avaliar suas possibilidades de consolidação no deteriorado cenário político-institucional atual.

Nossa hipótese é que o grau de êxito na implantação de políticas públicas participativas depende de duas variáveis: a) os níveis de institucionalização e de organização (política e administrativa) do poder público; b) a qualidade das relações entre Estado e sociedade civil, em que fatores como compromisso político, transparência e legitimidade são fundamentais para garantir níveis de confian-ça necessários para a realimentação do processo. Por institucionalização, compreendemos o processo histórico-social de consolidação de estruturas e procedimentos regulares no interior do Estado capazes de garantir espaços formais estáveis para o desenvolvimento de ações e relações políticas aos diversos agentes que compõem o sistema político - grupos de interesse, eleitores, legisladores, gestores públicos, burocratas etc. (STEINMO, THELEN e LONGSTRETH, 1992).

\section{Mesmo quando parecia aberto}

à participação social, o estado do Rio de Janeiro foi incapaz de fazer avançar políticas participativas na área da cultu-ra porque atuou de forma contraditória, desinstitucionalizando a área logo após enorme esforço de organizá-la. $\mathrm{Na}$ sequência, desativou essas políticas, reduzindo-as apenas ao cumprimento legal mínimo exigido pela Lei do Sistema. Esvaziadas politicamente em substância e legitimidade, as políticas culturais participativas deixaram de ser um compromisso da pasta, em sintonia com a retração da participação civil na administração pública ocorrida no Brasil a partir de 2016, e aprofundada ainda mais em 2019, com a extinção do Ministério da Cultura.

O artigo está dividido da seguin-te maneira: primeiramente, situaremos as contradições geradas pela nova institucionalidade diante das estruturas anteriores mobilizando o debate teórico neoinstitucionalista para compreender como a sociedade civil, em sua atuação no interior das instituições do Estado, pode contribuir com possibilidades mais democráticas de condução de políticas públicas. Em seguida, nos dedicaremos à análise empírica do caso do estado do Rio de Janeiro, demarcando seus avanços e retrocessos. Apontaremos os percalços ocorridos durante a construção do Sistema e como eles representam problemas para a participação social detectados pela literatura. Finalmente, na última seção, avaliaremos o quadro de estagnação das políticas públicas participativas no estado. A análise foi construída a partir de um duplo local de fala, já que os autores foram coordenadores técnicos do Plano Estadual e dos Planos Setoriais de Cultura, e são também pesquisadores do tema. Adicionalmente, foram realizadas entrevistas com gestoras que atuaram na SEC-RJ na execução de políticas culturais 3 .

3 Entrevistas com Bárbara Otero, gestora da Co-ordenação de Políticas Culturais; e Remata Costa, coor-denadora do Sistema Estadual de Bibliotecas (SEB), em 15.10.2018. 


\section{Paradoxos da Participação, Limites da Ação Política}

Respondendo aos compromissos assumidos pelo novo governo federal eleito em 2002, o Ministério da Cultura (MinC) foi capaz de aumentar os níveis de transparência e de participação da sociedade civil na construção de suas políticas culturais, um processo que teve início nas audiências realizadas em todo o país, por ocasião da discussão do Plano Nacional de Cultura e da reformulação da Lei Rou-anet (CALABRE, 2014).

Induzidos politicamente pelo Ministério e seduzidos pela possibilidade de parcerias de financiamento com o governo federal, diversos estados e municípios brasileiros assumiram também o compromisso de incorporar as represadas demandas por mais participação social na formulação de políticas de cultura, em particular na construção de mecanismos institucionais de organização de longo prazo; de representação política; e de financiamento da área.

O processo de redemocratização de cunho neoliberal no Brasil evidenciou, sobretudo na segunda metade dos anos 1990, um conflito entre forças emergentes de mercado e uma incipiente sociedade civil, com as primeiras produzindo desigualdades econômicas a instaurar formas diferenciadas de participação. Se o regime democrático pôde garantir uma igualdade formal a priori, a atua-ção autônoma do mercado gerou desigualdades substantivas, instaurando um paradoxo no sistema: aqueles que mais necessitavam participar eram justamen-te os que menos recursos para isso possuíam - instrução e capital social, capacidade de mobilização e recursos econômicos (AVRITZER, 2008; 2012). O móvel da participação é uma exclu-são anterior, mas, sem canais de vocalização suficientes e eficientes, não há veículos que possam viabilizá-la. Esse paradoxo é particularmente acentuado na área cultural brasileira, marcada por forte assimetria política entre os setores artístico-culturais, histórico de omissão do poder público, ausência de políticas culturais e alta precariedade administrativa e institucional (MAGALHÃES, 1985; BOTELHO, 2000; DORIA, 2003).

A criação do Sistema Estadual de Cultura do Rio de Janeiro foi um processo demarcado por sobressaltos, cujas contradições relativas encontram eco na literatura neoinstitucionalista sobre associativismo, que se dedica a compreender como o regime democrático pode ser aprimorado por meio da atuação da sociedade civil no interior das instituições do Estado. Argumentamos que fatores institucionais devem ser considerados na análise de políticas públicas, pois contribuem para modelar e definir interesses, preferências e objetivos dos agentes políticos (KRASNER, 1984). Instituições, porém, não operam de forma autônoma. Estão sujeitas a interferências das esferas da economia e da política, espaço onde a sociedade civil pode exercer influência considerável, modificando seu funcionamento e seus resultados.

Nos trade-offs entre sociedade civil e o Estado considerados no debate neoinstitucionalista, Jean Cohen e Andrew Arato oferecem uma perspectiva otimista (COHEN; ARATO, 1992). Para os autores, o fortalecimento da sociedade civil estruturaria novos níveis de pluralismo e ampliaria as demandas sociais existentes, em um fluxo constante de aprimoramento das condições dentro de um sistema democrático, expandindo como consequência o raio de atuação das instituições públicas. No Brasil, as políticas de participação social são em grande medida resultado desse processo de fortalecimento do associativismo e do pluralismo desde a redemocratização. 
De fato, os autores vêem a sociedade civil como locus de experimentação social para o desenvolvimento de novos tipos de solidariedade e de relações de cooperação e de trabalho por meio de associações transclassistas (Idem, p.38). Nessa dinâmica, as organizações culturais desempenham papel especial, uma vez que "contribuem para uma consciência de cidadania e seu desenvolvimento amplia o espaço da cultura como elemento importante na construção ativa e consciente na solução de seus problemas" (CARVALHO, 2009, p.20).

Contudo, a sociedade civil encontra limitações impostas pelas instituições vigentes. O paradoxo que se coloca é que, estando ela própria inserida em um quadro institucional, as transformações formuladas no seio da sociedade civil encontram frequentemente balizamentos colocados pelas instituições, gerando, em muitos casos, uma reprodução da-quele quadro institucional. Veremos que 0 estabelecimento de políticas de participação social pela SEC-RJ não encontrou propriamente impedimentos institucionais, mas uma resistência constante e crescente que culminou no fim desse experimento em 2019.

Preocupada com a insuficiên-cia da teoria democrática tradicional em oferecer um modelo político capaz de estimular a cooperação e a igual-dade social, pela ênfase que confere às liberdades individuais, Carol Gould (1988) ressalta a necessidade de encontrar formatos institucionais capazes de proteger e de ouvir a diversidade de interesses de minorias. Pela crítica do comportamento autointeressado dos indivíduos defendido pelo modelo neoliberal de associativismo, Gould, como também Benjamin Barber (1984) e Seyla Benhabib (2007) na teoria da democracia deliberativa, baseiam-se na concepção de política como processo. Isto é, através de uma dinâmica de interação os indivíduos tendem a aprimorar seu comportamento político e a fortalecer a institucionalidade. Há, nesses autores, um entendimento da necessidade de abertura de espaços institucionais capazes de arejar o Estado com democracia, tanto mais fortalecida quanto mais for capaz de assegurar diversidade cultural ao sistema político. Se obrigatória a democratização das instituições, através de relações mais equânimes entre os indivíduos, está claro que essas mesmas instituições têm também o poder de conformá- los. O caso brasileiro é exemplar nesse sentido, em que as instituições são marcadas por ações verticalizadas, mais preocupadas em controlar a cultu-ra do que em promovê-la (BARBALHO, 2007; RUBIM, 2007).

Contra esse ciclo vicioso, Gould afirma que a democratização extensiva das esferas econômica e política pode relativizar tanto premissas de mercado (e sua visão imediatista, voltada para o fim último do lucro), como de Estado (baseadas no controle burocrático e na centralização). Pela multiplicação de formas de expressão aparentes pelo processo associativo e pela organização de grupos sociais, a política deve se converter, então, de campo universalizante (quando entendido sob a ótica da estática institucional) em uma forma que abrigue e estimule transformações. A heterogeneidade dos gêneros de discurso deve ser afirmada como forma de manutenção e aprimoramento do regime (e de suas instituições). E nada mais próprio ao campo cultural do que a afirmação da diversidade.

O esforço normativo de Carol Gould, porém, esbarra na realidade concreta do estado do Rio de Janeiro, que suscita um conjunto de questões relativas à qualidade e à legitimidade da representação política. Um cenário como o fluminense, marcado por baixa institu- 
cionalização, baixo capital social e falta de credibilidade das instituições, coloca ainda o problema da concentração de recursos pelos grupos melhor organizados.

Como demonstraremos, apesar do empenho relativo do governo do estado do Rio para melhorar as relações entre Estado e sociedade civil na área da cultura, algumas barreiras à institucionalização das políticas não foram superadas - desorganização política e administrativa, falta de compromisso integral, de transparência e de legitimidade - limitando o alcance das políticas participativas e sedimentando as bases atuais de estagnação.

\section{Contradições e Avanços: o Caso Fluminense}

A experiência de desenvolvimento do Sistema Estadual de Cultura no Rio de Janeiro enfrentou ao longo do processo problemas de transparência e de legitimidade que contribuíram negativamente na geração de confiança, reforçando de modo continuado a baixa qualidade da relação entre Estado e sociedade civil. Reforça esse argumento a verificação de contraditórias idas e vindas do processo que explicitam a falta de prioridade da própria pasta da cultura e a falta de unidade do governo do estado com o compromisso de institucionalização de um processo participativo no ciclo da política cultural fluminense.

A primeira demonstração de incoerência política pelo Estado foi a coexistência de processos paralelos e contraditórios sendo executados simultaneamente pelo Poder Executivo, gerando confusão e falta de entendimento da direção política da SEC-RJ. Em novembro de 2009, a Secretaria dá início ao processo de construção participativa do Plano Estadual de Cultura que, conforme designação do próprio órgão, "foi desenvolvido com base no diálogo com gestores públicos dos 92 municípios do estado, representantes de entidades, agentes culturais, artistas, Comissão de Cultura da ALERJ e o MinC para apontar diretrizes e estratégias para as políticas públicas no estado do Rio de Janeiro"4.

Paralelamente, porém, o poder Executivo encaminha para a ALERJ o Projeto de Lei 1975/2009, que dispunha sobre a qualificação de entidades sem fins lucrativos como Organizações Sociais (OS), mediante contrato de gestão. $\mathrm{O}$ PL é votado em regime de urgência pelo Legislativo fluminense e aprovado em menos de trinta dias após a entrada na pauta da casa.

Não discutiremos aqui os ganhos e perdas relativos aos processos de privatização da gestão de equipamentos públicos, via estabelecimento de modalidades de transferência do poder de decisão sobre as estratégias de gestão de recursos públicos. Destacamos o fato de que entre 2009 e 2013 a SEC-RJ conseguiu aprovar aquela que ficou conhecida como a Lei das OS (Lei 5.498 de 07/07/2009), regulamentou o dispositivo legal por meio dos Decretos 4.256 de 2010 e 42.882 de 2011 e transferiu a gestão de parte significativa dos equipamentos culturais do estado para duas organizações até então desconhecidas no Rio de Janeiro.

Não questionamos a legitimidade do órgão gestor da cultura em pautar a

$4 \quad$ Disponível em: http://www.cultura.rj.gov.br/con-sulta-publica/planoestadual-de-cultura. Acesso em: 30 out. 2018.

$5 \quad \mathrm{O}$ PL entra na Ordem do Dia em 16 de ju-nho de 2009 e é aprovado pela ALERJ em 8 de julho. Disponível em: http://alerjln1.alerj.rj.gov.br/scpro0711. nsf/e00a7c3c8652b69a83256cca00646ee5/c987f75b $6 \mathrm{~d} 60576 \mathrm{e} 83257552006 \mathrm{c} 871 \mathrm{~b}$ ?OpenDocument. Acesso em: 30 out. 2018. 
política pública a partir da definição de sua agenda. Porém, entre 2009 e 2013, ao mesmo tempo em que a SEC-RJ transferia a gestão de diversos equipamentos importantes, definindo seus objetivos, metas e o desenho institucional de atuação das OS; conclamava a sociedade a debater e construir uma política cultural pública participativa para os mesmos setores culturais cobertos pela atuação dessas organizações. A partir de abril de 2012, em meio a essa contradição no âmbito do futuro Sistema Estadual de Cultura, eram realizadas audiências e consultas públicas para definir diretrizes prioritárias que orientariam a construção de planos setoriais da cultura no estado.6

Esse tipo de atuação ratifica o que Maria Alice Rezende de Carvalho (1995, p. 4) chamou de "baixa legitimação da au-toridade política do Estado", que tem por consequência aprofundar as reservas por parte da sociedade civil em relação ao quadro político-institucional

cujo privatismo "congênito" estreitou excessivamente a dimensão da pólis, condenando praticamente toda a sociedade à condição de bárbaros. A ex-pressão "cidade escassa" referese a essa dimensão residual da cidadania e, portanto, a sua parca competência para articular os apetites sociais à vida política organizada isto que, no mundo das ideias políticas, caracte-rizaria a "cidade liberal-democrática". (Idem, p.4)

É nessa cidade liberal-democrática, escassa para a maioria da população que nela vive, que os conflitos e dilemas em torno da institucionalização de novas

6 Planos Setoriais de Cultura. Disponível em: http://www.cultura.rj.gov.br/planos-setoriais. Acesso em: 18 jan. 2015. formas de participação da sociedade ci-vil nos processos decisórios das políticas coexistem com os velhos vícios do poder estabelecido.

Um segundo fator que incidiu so-bre a credibilidade do processo ocorreu por suspensões e lacunas no seu desenvolvimento. Durante os cinco anos (2010 a 2015) em que o Sistema e o Plano Estadual de Cultura do Rio de Janeiro estiveram em fase de construção e de debates públicos, em dois deles (durante quase todo o ano de 2011 e entre 2014 e 2015) nenhuma ação com a sociedade civil foi realizada, por questões internas de descontinuidade na estrutura profissional do órgão estadual gestor de cultura (2011); e por conflitos político-eleitorais entre a SEC-RJ e a Casa Civil do governo do estado (2014-2015).

Esses intervalos acarretaram desmobilizações dos atores sociais envolvidos, além de uma perda substantiva nos esforços de cumprimento de uma metodologia que levasse ao objetivo original proposto. Como consequência, escutas para diagnóstico territorial tiveram que ser parcialmente refeitas em algumas audiências e reuniões em 2012, quando o processo foi retomado depois da primeira paralisação. Já na tramitação do Projeto de Lei 533/2015, que instituiria o Sistema Estadual de Cultura e seus componentes, também houve contradições que ajudam a compreender os dilemas da participação.

Após cerca de três anos (2010 a 2012) de escutas públicas e abertas que objetivavam a produção de um diagnósti-co da cultura fluminense, e de um esforço particular de mobilização política pelo poder público em todas as regiões do esta-do, foi produzido um texto-base da Lei e do Plano Estadual de Cultura (PEC), que absorveu o núcleo das propostas apresentadas pela sociedade civil para a área. 
A minuta para consulta pública do PEC, apresentada e distribuída pela SEC-RJ em janeiro de 2013 para a segunda rodada de discussões, chamava a atenção por uma série de inovações que distinguiam o Plano de projetos de outros estados da federação e do Plano Nacional, fruto da capacidade de escuta e de incorporação de demandas próprias demonstrada pela SEC -RJ. Entre as novidades trazidas pela sociedade civil, destacavam- se o protagonismo juvenil na cultura, com reaproximação entre educa-ção e cultura; a incorporação de diversas estratégias de valorização do interior; a imbricação entre cultura e formas sus-tentáveis de produção com uma diversi-dade de fontes de fomento para a área, que passaria a ser dotada de um fundo próprio sujeito ao controle por um comitê gestor com participação da sociedade ci-vil; entre outros avanços.

Em 14 de dezembro de 2012 foi aberta nova etapa de consultas pela internet, em paralelo à realização de outras dez audiências presenciais abertas por todas as regiões do estado ao longo de 2013, como forma de garantir canais de escuta pelo poder público. Em dezembro de 2013, a versão consolidada pela SEC-RJ da Lei e do Plano Estadual de Cultura foi encaminhada oficialmente para a Casa Civil do governo (que já conhecia o teor do documento), onde permaneceu por um período de um ano e meio (2014 e boa parte de 2015), imobilizando o andamento dos trabalhos, esfriando as relações conquistadas pela Secretaria com a sociedade civil, prejudicando a transparência na condução do processo, com evidente prejuízo de credibilidade e da confiança pública que haviam sido conseguidas com grandes dificuldades. Importante ressaltar que o texto encaminhado para a Casa Civil já não contou com uma sistematização participativa das contribuições da sociedade civil, recebendo mais uma compilação dos técnicos da SEC-RJ ou simplesmente o veto de algumas das demandas das consultas públicas pela secretária de cultura.

O exemplo é uma evidência da fraqueza política da pasta, sua falta de prestígio no interior do próprio governo, e os reduzidos acompanhamentos e pressões pela sociedade como fatores negativos na tentativa de promoção de maior institucionalização da Secretaria. A SEC-RJ chegou a ficar excluída, por exemplo, de um edital de fortalecimento dos Sistemas de Cultura, lançado pelo MinC em maio de 2014 apenas para estados que já os tives-sem aprovados?.

O ano eleitoral de 2014 evidenciou uma disputa política no interior do governo do estado, motivando um conflito sobre o limite da renúncia fiscal para a cultura proposto na lei (Art. 24), que congelou definitivamente o diálogo da pasta com a sociedade civil. Inicialmente acordada com a Casa Civil em 0,5\% da arrecadação do ICMS fluminense, o valor proposto foi reduzido pela Casa Civil para $0,4 \%$, depois do texto parado há meses fora do controle da SEC-RJ. Isso fez com que o texto não fosse logo encaminhado para a tramitação na ALERJ. Ao longo de 2014, entre promessas de liberação pela Casa Civil e cobranças à SEC-RJ pelos setores que haviam prestado seu engajamento e energia política para o processo, o texto ficou paralisado à espera da definição dos resultados eleitorais.

A eleição do Luiz Fernando Pezão, candidato do governador Sérgio Cabral Filho, e a recomposição pós -eleitoral das forças políticas valorizaram a Secretaria

\footnotetext{
7 http://www.cultura.gov.br/inscricoes-abertas/-/ asset_publisher/kQxYTMokF1Jk/content/sai-minc-lanca-edital-de-fortalecimento-do-snc/10883. Acesso em: 15 jan. 2016
} 
de Estado de Esporte e Lazer, que incorporou 'Juventude' ao nome da pasta em janeiro de 2015, passando a ser comandada pelo filho do ex-governador, o neófito Marco Antônio Cabral. O imobilismo, a partir daí, se acentuou com a possibilidade do valor de $0,4 \%$ ser agora repartido entre as duas secretarias. Além disso, o processo de construção participativa esbarrou em limites que excediam a capacidade e a autonomia institucional da própria SEC-RJ em conduzir e resolver o processo que ela havia dado início. A crise econômica que se abateu sobre as finanças do estado só contribuiu para aumentar a disputa, congelar a política e, a essa altura, colocá-la em xeque perante a sociedade civil, que não teve conhecimento do casuísmo desses movimentos.

Infelizmente, o conflito foi desfeito por motivos menos nobres do que a pressão de uma sociedade civil atenta e atuante, mas por razões intragovernamen-tais. Um rumor de que o MinC lançaria novo edital, voltado ao fortalecimento de sistemas municipais de cultura - mas condicionando o financiamento de projetos à obrigatoriedade de que seus estados também tivessem sistemas aprovados - ge-rou grande pressão de prefeituras sobre a SEC-RJ. Mesmo sem confirmação oficial, a informação oficiosa foi importante para despertar a Casa Civil, num contexto de penúria fiscal, liberando o texto para a Assembleia Legislativa.

Sobre esse último ponto, cumpre destacar a importância que as instân-cias sub-nacionais deram à expectativa de financiamento por parte do governo federal, como um dos fatores críticos de adesão ao Sistema Nacional de Cultura e acelerado esforço de criação das estruturas institucionais que compusessem os Sistemas municipais.

$\mathrm{Na}$ tramitação da lei, a ALERJ promoveu-a em regime de urgência, com parca mobilização política pela sociedade civil e pouca participação das regiões do estado, aprovando a Lei Estadual de Cultura em 26 de junho de 2015, não sem que a base majoritária do próprio governo na Assembleia reduzisse para $0,25 \%$ o percentual do ICMS destinado ao fomento da cultura (ficando os outros $0,25 \%$ que comporiam o valor original de $0,5 \%$ destinados apenas para projetos esportivos). Os agentes de cultura estiveram alheios a esses movimentos e o suposto edital do MinC com cláusulas condicionantes aos estados da federação jamais foi publicado.

A conclusão do processo é exemplar no que diz respeito aos dilemas da participação da sociedade civil destacados pela teoria neoinstitucionalista. Sem instâncias formais de acompanhamento e pressão pelos grupos organizados e sem transparên-cia sobre a natureza do conflito dentro do próprio governo, a sociedade civil, após ter sido encorajada a tomar posi-ção e a contribuir para a formulação de uma política estadual de cultura, tomou conhecimento, a posteriori, de um rito de aprovação acelerado, sem tempo e sem condições para novo esforço de remobilização, depois de um ano e meio sem informações sobre o processo. O texto aprovado sofreu emendas consideradas positivas, que tornaram obrigatórios a descentralização de recur-sos para o interior do estado (art. 21,

l) e investimentos em ações culturais para pessoas com deficiência (art. 21, III), por exemplo. A promoção de políti-cas de gênero, entretanto, foi suprimida do Plano Estadual de Cultura (Eixo 2, estratégia 2.1.2) por força da bancada cristã na ALERJ, que logrou ainda in-cluir entre os objetivos expressos do Sistema a promoção de manifestações religiosas (art.3, XI), pontos em que a organização da sociedade civil poderia ter feito significativa diferença. 
Mesmo aprovando uma lei que pode ser considerada avançada e construída com a colaboração dos agentes da cultura, a SEC-RJ perdeu a oportunidade de fortalecer vínculos com a sociedade civil ao não ser capaz de integrá-la devidamente no momento decisivo. A despeito da perda de valores de renúncia fiscal ocorrida com a mudança do texto do artigo 24 aprovado, a condução final do processo determinou um prejuízo político de difícil mensuração, pois a falta de transparência incidiu tanto na confiança dos atores que se envolveram quanto na própria legitimidade da política. Um desgaste que incide sobre a continuidade de iniciativas que se proponham participativas e sobre sua capacidade de converter propostas oriundas da sociedade civil em ações de governo.

Apesar das disputas internas, de resto naturais à dinâmica política, o Estado precisa assegurar unidade e coerência de governo, do início ao fim do processo, quanto ao compromisso com políticas participativas, de modo a não expor suas fragilidades à sociedade. $\mathrm{O}$ discurso da participação cívica na produção e execução de políticas culturais envolve desafios que remetem a formas mais institucionais de conduzir a relação com os agentes da sociedade civil. Mais grave, porém, do que evidenciar suas contradições e tornar questionável seu compromisso político é o risco de não poder contar com a energia cívica e a contri-buição dos movimentos sociais no futuro, retrocedendo novamente a patamares de um passado recente.

O que se presenciou na sequência da aprovação da Lei 7.035, regulamentada pelo Decreto 45.419/2015, foi um conjunto de esforços bastante frágeis frente à conjuntura política de crise que se instaurou no governo fluminense. De todas as instâncias previstas para a gestão do Sistema, bem como os mecanismos pla- nejados para dar suporte a elas, apenas - Conselho Estadual de Cultura (hoje Conselho Estadual de Política Cultural) consolidou-se após a constituição do aparato normativo aprovado pelo legislativo fluminense. $O$ fato de ter tido regulamentação imediata após a aprovação da lei permitiu que essa instância fosse rapidamente instalada e seus conselheiros eleitos e empossados. No entanto, como veremos a seguir, com limitada capacidade de influenciar a política cultural do órgão (a despeito de ter sido a instância institucional mais contundente no episódio de reversão da decisão de fechamento da SEC-RJ no início de 2017).

Importa salientar que a lei que instituiu o Sistema Estadual de Cultura do Rio de Janeiro (SIEC-RJ) previu como suas instâncias de gestão as seguintes institucionalidades: a Secretaria de Estado de Cultura como sua coordenadora; o Conselho Estadual de Política Cultu-ral; Conselho Estadual de Tombamento; Conferências Estadual e Regionais de Cultura; Fóruns Setoriais e Regionais; Comissão de Cultura da ALERJ, órgãos públicos gestores e sistemas de cultura dos municípios fluminenses; Conselhos Municipais de Cultura; Conselhos Municipais de Proteção do Patrimônio Cultural e a Comissão de Intergestores Bipartite (que deveria ser composta de três representantes indicados pela SEC- RJ e dois pelo conjunto dos secretários e dirigentes municipais de cultura).

Além dessas instâncias, os instrumentos de gestão previstos a serem implementados e geridos por elas se apoiariam no tripé planejamento, financiamento e capacitação, por meio principalmente do Plano Estadual de Cultura. Além do PEC, a lei prevê o Programa Estadual de Fomen-to e Incentivo a Cultura, que dá indicativos do direcionamento dos fundos, fontes de financiamento, beneficiários, bem como modalidades de aplicação, prevendo um 
limite máximo de $40 \%$ para o investimento dos recursos na capital; e o Programa de Formação e Qualificação Cultural, uma arrojada estratégia de capacitação dos agentes de cultura em todo o estado.

A despeito de todos os esforços implementados pelo governo do estado e o atendimento de participação da socieda-de civil na construção desses importantes mecanismos institucionais, verifica-se atualmente um quadro de total estagnação e retrocesso das políticas culturais participativas no estado do Rio de Janeiro. Pior do que isso, os instrumentos de gestão que deveriam balizar a implementação de todas as ações da pasta foram abandona-dos e a SEC-RJ retornou às práticas ante-riores ao ano de 2009.

\section{Estagnação das Políticas Culturais Fluminenses}

O desenvolvimento de um Sistema Estadual de Cultura, iniciado no final de 2009 com um entusiasmado chamamento à participação social pela secretária de Estado de Cultura, foi marcado por uma inconstância de priorização política, registrando momentos de completa paralisia. Essa dinâmica irregular de diálogo com a sociedade civil é uma marca presente em iniciativas que partem da SEC-$R J_{8}$ quanto à implantação de políticas participativas, o que corrobora a constatação de que é bastante incipiente a estrutura de participação social construída pelo Sistema Estadual de Cultura.

Depois da prejudicada mobilização da sociedade nos ritos de aprova-ção da lei que criou o Sistema Estadual de Cultura, em julho de 2015, o Decreto

8 A partir de 2019 o órgão passa a se chamar Secretaria de Cultura e Economia Criativa (SECEC).
45.419, que regulamentou o Conselho Estadual de Política Cultural (CEPC), seria publicado em outubro daquele ano. Em sua composição, o CEPC conta com 32 conselheiros, sendo dezesseis membros titulares e respectivos suplentes, representantes da sociedade civil: dez membros das regiões do estado eleitos nas Conferências Regionais de Cultura convocadas e organizadas pela SEC-RJ, mais seis membros representantes dos segmentos culturais (artes cênicas, artes visuais, audiovisual, música, literatura e cultura popular), eleitos virtualmente. Os outros dezesseis membros titulares e suplentes, representantes do poder público, são compostos por dois membros da Comissão de Cultura da ALERJ e outros quatorze representantes, indicados pelo governo estadual, dentre os quais, pelo menos um do poder público estadual, um representante do poder público municipal, um membro de instituição acadêmica e um de instituição de relevância cultural no estado do Rio de Janeiro. Todos indicados diretamente pelo poder público estadual, sem eleição.

$\mathrm{Na}$ sequência de sua publicação, em apenas 60 dias, foram realizadas 20 reuniões públicas para eleição dos novos conselheiros de política cultural (10 Conferências Regionais, antecedidas de 10 reuniões prévias às Conferências), abrangendo todas as 92 cidades do estado, onde foram eleitos os 16 membros representantes da sociedade civil. Nesse curto período teriam sido cumpridas etapas de: planejamento dos regulamentos da eleição; esclarecimento do processo, para que as pessoas pudessem efetivar sua participação; divulgação dos eventos; mobilização local (e virtual), para que se conhecessem os candidatos; organização logística e efetiva realização da eleição de conselheiros e suplentes.

O extinto Conselho Estadual de Cultura do RJ, criado em 4 de abril de 
1975 pelo Decreto-Lei $n^{\circ} 589$, contava com 21 membros efetivos e 4 suplentes indicados entre pessoas de notável saber e experiência nos diversos campos da cultura, que eram nomeadas pelo governador do estado. Foram necessários 40 anos para que um componente participativo pudesse finalmente penetrar em uma estrutura redesenhada para influenciar a forma como as políticas públicas de cultura do estado do Rio de Janeiro passariam a ser pensadas no futuro. Seria mais que legítima a construção de um processo eleitoral elaborado em parceria mais estreita com a população e agentes culturais das 92 cidades fluminenses. Em vez disso, as 10 Conferências Regionais organizadas para esse fim sucederam-se umas às outras em eventos que reuniram pouco mais de mil pessoas em todo o estado.

O CEPC constitui a principal instância participativa prevista na estrutura ge-ral do Sistema, e como tal desempenhou papel fundamental na resistência às sucessivas tentativas de esvaziamento das políticas de cultura fluminenses, desde a sua reestruturação. Além dele, outras duas instâncias foram fortalecidas nessa estratégia de arquitetura compartilhada: os Fóruns Regionais e os Fóruns Setoriais e Artístico-culturais, que são elementos integrantes do Sistema Estadual de Cultura. Juntamente com o CEPC, os Fóruns têm tentado dar continuidade ao modelo de diálogo iniciado no âmbito do Sistema, seja como espaço de interlocução com o governo na capital, seja na pressão para que os instrumentos construídos nas gestões anteriores se efetivem:

Nessa diretiva, foi regulamentada pelo Decreto no 45.419 , de 19 de

9 Um histórico do CEC pode ser consultado na página do órgão: http://www.cultura.rj.gov.br/historico-conselho. Acesso em: 18 maio 2019.
Outubro de 2015, [a] existência dos Fóruns de Cultura, tanto regionais como dos segmentos culturais, sendo a Secretaria de Estado de Cultura do Rio de Janeiro (SEC) responsável por articular os Fóruns setoriais e regionais de Cultura, junto ao Conselho Estadual de Política Cultural (CEPC). Ressalta-se que os Fóruns são estabelecidos como instâncias de assessoramento e consulta do CEPC e tem como competência contribuir na construção de estratégias para a implementação das diretrizes da Política Estadual de Cultura 10.

Além dessas instâncias, que avançam no propósito de consolidar um ambiente mais arrojado para a cultura, e criadas para serem referências norteadoras do novo perfil de políticas que o Sistema pretendia inaugurar, figuram 0 Plano Estadual de Cultura e os Pla-nos Setoriais, com diretrizes de médio e longo prazo construídas a partir de um amplo processo de negociação com a sociedade civil. Ambos sofreram com a inconstância de priorização política. Durante os anos de 2017 e 2018, em virtude da articulação do CEPC e dos Fóruns, algum avanço foi registrado, especialmente no que se refere ao estabelecimento de metas a serem cumpridas em prol do desenvolvimento cultural do estado (criação de grupos de trabalho no interior do CEPC e discussões ini-ciais). Porém, não foram verificados avanços concretos na implementação de nenhuma ação. Tampouco encon-tram-se disponíveis informações atuali-zadas nos canais do órgão em relação

à articulação das metas e programas dos instrumentos de gestão construídos

10 Blog do CEPC. Disponível em: http://conseIhoestadualculturarj.blogspot.com/p/foruns-regionais-e-artistico-culturais.html. Acessado em: 18 maio 2019. 
entre 2009 e 2015. De fato, no âmbito do Sistema, depois de 2015, as únicas instâncias de gestão participativas regulamentadas foram o Conselho e os Fóruns e um único instrumento, o Fundo Estadual de Cultura. Já os planos participativos (estadual e setoriais), que mobilizaram milhares de pessoas ao longo de sua construção, ainda não se tornaram realidade. Alguns setores, como Livro e Leitura e Audiovisual, em virtude dos avanços nos debates anteriores a 2015, ainda evoluíram na articulação de parcerias e na realização de ações pontuais. No momento em que redigimos este artigo, no entanto, todos os planos setoriais encontram-se completamente abandonados em função das novas diretrizes na pasta.

O cenário registrado nesses quatro anos posteriores à criação da Lei do Sistema Estadual de Cultura é de retrocesso a patamares inimagináveis em 2009. A alternância de secretários da pasta, por exemplo, retrocede mais de 10 anos, quando cada gestão tinha pelos menos quatro secretários de Cultura. $\mathrm{Na}$ verdade, essa é uma realidade da pas-ta desde a sua criação, quando apenas os governos pós-fusão 11 (Floriano Fa-ria Lima, de 1975 a 1979; e Antônio de Pádua Chagas Freitas, de 1979 a 1983) completaram a gestão com apenas um secretário do início ao fim do mandato.

Entre o período de 2015 e 2019 quatro secretários ocuparam a titularidade da pasta, o que compromete seriamente a continuidade das políticas e acaba por produzir desconfiança no canal deliberativo que se pretendia construir, esvaziando a legitimidade desses espaços. Um

11 Fusão dos estados da Guanabara e do Rio de Janeiro, oficial a partir de 1975, ano em que foi criado o órgão estadual de gestão da cultura (que aglutinava a pasta da educação, à época). fato agravado pelo retorno da prática, outrora comum na SEC-RJ, de entregar sua titularidade a um aliado político do governador que não necessariamente tenha aproximação com o campo cultural, como moeda de troca eleitoral.

A crise econômica enfrentada pelo estado do Rio de Janeiro desde mea-dos de 2016, quando o governo decre-tou calamidade pública financeira, fez-se sentir duramente na estrutura funcional da SEC-RJ. A partir de então houve uma perda significativa no orçamento da pasta, encolhimento de $30 \%$ do quadro funcional de técnicos, contingenciamento de salários e reestruturação (leia-se esvaziamento) daquilo que havia sido o principal legado da gestão anterior iniciada em 2007. Referimo-nos à modernização da estrutura do órgão a partir da criação de superintendências e áreas direcionadas exclusivamente ao desenvolvimento de setores da cultura e das artes, até então tratados no conjunto de outras políticas, uma novidade à época. Sob esse quadro geral de esvaziamento completo, não é possível imaginar um horizonte em que a retomada de políticas de participação social e a opção pela cultura como fator de desenvolvimento voltem a ser prioridades do Estado.

\section{Considerações Finais}

Esse artigo, embora bastante crítico quanto aos desafios enfrentados no processo de institucionalização do Sistema Estadual de Cultura do Rio de Janeiro, pretende registrar o potencial que os avanços conquistados até aqui podem significar em termos de renovação das estratégias adotadas pelos gestores públi-cos no campo cultural fluminense.

Uma das conquistas foi sem dúvida a maior diversidade de agentes que se comprometeram com a proposta, para 
além da classe artística (grupos comunitários, usuários dos equipamentos de cultura, organizações não-governamentais da área, projetos sociais e pontos de cultura), demonstrando uma inflexão na forma como a própria cultura é en-tendida pelo Estado, não se limitando às artes e ao patrimônio simbólico, mas às formas de sociabilidades historicamente construídas no território. Outros ganhos de institucionalização se fazem obser-var, ainda que timidamente. O Sistema Estadual de Cultura estabeleceu bases legais que fortalecem o processo de institucionalização do poder público na área cultural, por meio de mais participação cívica na formulação, acompanhamento e controle das políticas. Sua efetividade, no entanto, enfrenta um paradoxo institucional, pois obriga que o Estado se reestruture segundo essa lógica permeável, tarefa que só poderá ser realizada na medida em que as pressões da sociedade civil se fizerem atendidas.

Nesse sentido, o Conselho Estadual de Política Cultural, reformulado para responder a exigências democráticas - eleito e regionalmente representativo, paritário, plural e deliberativo - passa a assumir papel central como instância de articulação e pressão da sociedade civil sobre o processo de fortalecimento da institucionalização do domínio da cultura no estado do Rio de Janeiro. A eleição direta ocorrida em dezembro de 2015 e em fevereiro de 2016, por meio de conferências regionais e eleição virtual, restitui e renova o órgão após um vazio institucional de quatro anos ${ }_{12}$, depois de expirado

12 Os conselheiros possuíam mandato de quatro anos, podendo ser reconduzidos pelo governador do es-tado por mais dois períodos. Os 25 conselheiros empos-sados em 17 de abril de 2007 (21 titulares e 4 suplentes) não foram reconduzidos, tendo em vista que a SEC-RJ já planejava uma alteração na estrutura do Conselho quando do término do mandato, em 2011. o mandato do último Conselho, de resto inexpressivo e sem legitimidade porque até então composto somente por membros indicados pelo poder público.

Também os editais de chamada pública foram incorporados pela SEC-RJ como prática regular de promoção cultural, muito embora o volume de recursos investidos em fomento pelo órgão ainda seja menor do que aquele distribuído por essa modalidade, portanto suscetível a voluntarismos, preferências pessoais e à continuidade da 'política de balcão'. São contradições geradas por novas institucionalidades a conviver entre obsoletas formas de gestão pública. Administrativamente, entretanto, a SEC-RJ estabeleceu uma Coordenação de Políticas Culturais em 2015, voltada especificamente para a regulamentação e a implantação dos diversos instrumentos do Sistema (mas depois encerrada, em 2019), com destaque para a execução do Programa de Formação e Qualificação Cultural, que chegou a ter duas edições.

Por fim, o aumento da participação social foi relevante também para forçar a SEC-RJ a assumir sua vocação de ente estadual, isto é, a de trabalhar como integrador de políticas junto aos municípios fluminenses em articulação com o governo federal. Isso havia se materializado, em particular, com a terceira edição do Programa de Apoio ao Desenvolvimento Cultural dos Municípios (PADEC), promovido pela SEC-RJ em 2014-2015, junto com o MinC e a Fundação de Apoio à Escola Técnica (FAETEC), para estimular a criação de sistemas de cultura em municípios do estado. Ao fazer isso, a SEC-RJ assumiu o papel de dinamizadora de sistemas, sinalizando positivamente para a sociedade seu compromisso político com a institucionalização da área cultu-ral em todo o estado e não somente de suas próprias estruturas. 
Por outro lado, apesar desses avanços, não se pode deixar de regis-trar que o nível reduzido de organização dos grupos políticos e a baixa confiança no Estado pelos agentes da área cultu-ral exerceram impacto negativo sobre a qualidade geral do processo de elaboração participativa do Sistema Estadual de Cultura, a despeito da promulgação de uma nova lei. A possibilidade de realização das políticas, malgrado a disposição do Estado, esbarra ainda na alta dependência das vontades pessoais de gestores, dado o baixo nível de institucionalização do poder público. Isso ficou patente com o encerramento das políticas setoriais em 2018, cujo processo foi negligenciado pela gestão subsequente à que deu início a esse conjunto de políticas participativas. As políticas setoriais ficaram então ao desejo particular de superintendentes continuá-las ou engavetá-las, com danos para a credibilidade da pasta perante os segmentos culturais que contribuíram no processo para assistirem novamente seus esforços frustrados, sem a devida entrega dos resultados anunciados. Este fator também contribuiu para a redução de confiança, que por sua vez contribui para enfraquecer a própria instituição. A indisposição de alguns gestores com políticas de participação social foi se tornando cada vez maior, na mesma medida em que a conjuntura nacional ia também se indispondo com formas mais democráticas de se fazer política. A indisposição inicial se converteu em negligência a partir de 2016 para se tornar abando-no a partir de 2019. Sob o novo gover-no eleito em 2018, a Coordenação de Políticas Culturais foi encerrada e todas as informações relativas - legislação, registros oficiais, notícias dos eventos realizados com a sociedade e toda a documentação existente - foram excluídas em 31 de maio de 2019. Com a decisão de reformular totalmente seu site oficial, a Secretaria determinou assim o apaga- mento de 10 anos de trabalho e o fim de toda memória institucional do processo, razão adicional para que estudos como este sejam produzidos e publicados. Neste sentido, o estado do Rio de Janeiro é um reflexo da conjuntura nacional de precaução contra a participação cidadã nas instituições do Estado e de retração democrática.

Este artigo buscou apresentar os percalços políticos de um processo desencadeado nos últimos dez anos no estado do Rio de Janeiro com a introdução do pressuposto participativo no campo das políticas públicas de cultu-ra do estado. Contrapondo-se ao patrimonialismo de estruturas clientelistas arcaicas que historicamente ditaram 0 modus operandi do campo cultural, foi implementado um conjunto de ações que se pretendia transformador de uma realidade, mas que, passada uma década, configura-se como uma tentativa parcial de modernização que não conseguiu se realizar como estruturante de uma nova realidade.

\section{Referências}

AVRITZER, Leonardo. Instituiçes participativas e desenho institucional: algumas considerações sobre a variação da participaço no Brasil democrático. Revista Opinião Publica. Campinas, v. 14, n. 1, p. 43-64, junho, 2008.

AVRITZER, Leonardo. Sociedade civil e Estado no Brasil: da autonomia a interdependencia politica. Revista Opiniao Publica. Campinas, v. 18, n. 2, p. 383-398, novembro, 2012.

BARBALHO, Alexandre. Políticas culturais no Brasil: identidade e diversidade sem diferença. In: RUBIM, A. A. C.; BARBALHO, A. (orgs.) Políticas Culturais no Brasil. Coleção Cult, v. 2. Salvador: EDUFBA, 2007. p. 37-60. 
BOTELHO, Isaura. Romance de Formação: Funar-te e política cultural - $1976-1990$. Rio de Janeiro: Edições Casa de Rui Barbosa, 2000.

BARBER, Benjamin R. Strong Democracy: Participatory Politics for a New Age. Berkeley: University of California Press, 1984.

BENHABIB, Seyla. Sobre um modelo deliberativo de legitimidade democrática. In: WERLE, Denílson Luiz; MELO, Rúrion Soares (orgs.) .Democracia Deliberativa. São Paulo: Editora Singular, Esfera Pública, 2007, p.47-79.

BOTELHO, Isaura. Dimensões da cultura e políticas públicas. São Paulo em Perspectiva. São Pau-lo, 15 (2), p. 73-83, abril/junho de 2001.

CALABRE, Lia. Políticas culturais no Brasil: dos anos 1930 ao século XXI. Rio de Janeiro: FGV, 2009.

CALABRE, Lia. Política Cultural em tempos de democracia: a Era Lula. Revista do Instituto de Estudos Brasileiros, São Paulo, n. 58, Junho 2014, p. 137-156.

CARVALHO, Cristina Amélia. O Estado e a participação conquistada no campo das políticas públicas para a cultura no Brasil. In: Políticas Culturais: reflexões e ações, Observatório Itaú Cultural/Edições Casa de Rui Barbosa, São Paulo, 2009, p. 19-33.

CARVALHO, Maria Alice Rezende de. Cidade Escassa e Violência Urbana. Série Estudos. IUPERJ: Rio de Janeiro, n. 91, Agosto, 1995.

COHEN, Jean L.; ARATO, Andrew. Civil Society and Political Theory. Cambridge: MIT Press, 1992.

CONSELHO ESTADUAL DE POLÍTICA CULTURAL. Relatório de Formação do Conselho Estadual de Política Cultural: biênio 2016-2018. Disponível em: http://www.cultura.rj.gov.br/leiestadual/ upload/Anexo5.pdf. Acesso em: 18/05/ 2019.

DORIA, Carlos Alberto. Os Federais da Cultura. São Paulo: Biruta, 2003.

GOULD, Carol C. Rethinking Democracy. Freedom and social cooperation in politics, economy and society. Cambridge University Press: Nova lorque, 1988.

GOVERNO DO ESTADO DO RIO DE JANEIRO.

Lei 7.035/2015 - Sistema Estadual de Cultura do Rio de Janeiro. Disponível em: http://www. cultura.rj.gov.br/editais/doceditais/lei_siste-

ma_estadual_de_cultura_do_ri.pdf. Acesso em: 15/01/2016.

KRASNER, Stephen D. Approaches to the State: Alternative Conceptions and Historical Dynamics. Comparative Politics, v. 16 , n. 2, p. 226-246, jan 1984.

MAGALHAES, Aloisio. E Triunfo? A questão dos bens culturais no Brasil. Rio de Janeiro: Fundação Roberto Marinho, Nova Fronteira; Brasilia: FNPM, 1985.

RUBIM, Antônio Albino Canelas. Políticas culturais no Brasil: tristes tradições, enormes desa-fios. In: RUBIM, A. A. C.; BARBALHO, A. (orgs.) Políticas Culturais no Brasil. Coleção Cult, v. 2. Salvador: EDUFBA, 2007. p. 11-36.

RUBIM, Antonio Albino Canelas. Políticas Culturais do Governo Lula/Gil: Desafios e Enfrentamentos. INTERCOM - Revista Brasileira de Ciências da Comunicação, SP, v. 31, n.1, p. 183-203, jan./jun. 2008.

STEINMO, Sven; THELEN, Kathleen;. LONGSTRETH, Frank (eds.). Structuring Politics: Historical Institutionalism in Comparative Analysis. Cambridge: Cambridge University Press, 1992. 